\title{
Como dialogar, se as diferenças estão silenciadas na escola?
}

\section{Carolyna Ferreira Barroca}

carolynabarroca@gmail.com

ANDRADE, Marcelo (Org.) Diferenças silenciadas: pesquisas em educação, preconceitos e discriminações. Rio de Janeiro: 7 letras, 2015.

O livro Diferenças silenciadas, como exposto em sua apresentação, é resultado de pesquisas individuais e coletivas, concluídas e em andamento, no Grupo de Estudos sobre Cotidiano, Educação e Culturas, da Pontifícia Universidade Católica do Rio de Janeiro (Gecec/PUC-Rio). O que congrega as investigações é a temática do preconceito e da discriminação e suas possibilidades de superação no campo da educação. Os pesquisadores partem da premissa de que o silenciamento e a não aceitação das diferenças são os geradores das diversas situações de violências no cotidiano escolar e apresentam, em nove capítulos, alguns dos silenciamentos mais frequentes no ambiente formal de ensino, além de possibilidades de atuação e estratégias para a superação dessas situações que negam vez e voz à diferença.

Como questão central da obra, os pesquisadores buscam responder a seguinte pergunta: Como, em uma sociedade tão multicultural como a nossa, ainda persistem as dificuldades de se dialogar com as diferenças, dentro do contexto escolar? A partir de uma perspectiva interdisciplinar - exposta também na formação acadêmica dos membros do grupo de pesquisa (pedagogia, filosofia, história, biologia, sociologia, política, linguística) -, o livro apresenta discussões fundamentais para professores em formação inicial e/ou continuada, a fim de trabalhar o tema das diferenças na escola.

O capítulo inicial da obra se propõe a apresentar alguns aspectos para o aporte teórico do livro. Por meio da defesa de uma educação intercultural centrada em uma concepção ético-filosófica sobre o diálogo, Marcelo Andrade e Luiz Câmara apresentam uma possibilidade analítica e prática de enfrentamento das exclusões que o ambiente escolar proporciona. O livro é dividido em três partes, cuja primeira aponta as diferenças entre o silêncio e o silenciamento. Para o conceito de silêncio, recorrem a Hannah Arendt e seu entendimento sobre o "dois-em-um", no qual a 
reflexão introspectiva pressupõe perguntas e respostas que o indivíduo faz a si mesmo. Há ainda o silêncio como uma estratégia de enfrentamento de conflitos, quando não há diálogo, pois o interlocutor não é considerado confiável. O conceito de silenciamento pressupõe uma imposição, uma atuação proposital de não deixar falar, não deixar expor, não ouvir. A segunda parte apresenta a ética do discurso, tendo por base as contribuições teóricas de Adela Cortina, como proposta de sustentação de uma educação intercultural e suas principais contribuições para uma ética dialógica, na qual as diferenças não serão hierarquizadas, excluídas ou silenciadas. Nesse sentido, uma mudança do "eu penso" para o "nós argumentamos" é essencial na formação de juízos morais e presença fundamental na escola, na opinião dos autores. Por fim, a terceira parte deste capítulo apresenta os capítulos subsequentes, buscando orientar os leitores numa leitura sensível às temáticas abordadas.

O segundo capítulo é de autoria de Adela Cortina e suas contribuições teóricas na defesa de que todos os indivíduos podem e devem desenvolver uma consciência moral, desde que se tenha o interesse de agir de acordo com essa consciência. Trabalhando desde a ideia de moralidade coletiva, a filósofa espanhola nos apresenta um questionamento: como incentivar uma moral coletiva, dado que essa possibilita maiores ideais de justiça coletiva social, em nossa sociedade, de forma a secundarizar o individualismo? O investimento em uma educação, na qual tais preceitos morais sejam desenvolvidos, surge como possibilidade. Assim, a partir do questionamento sobre o que seria educar moralmente, Cortina traça um panorama das tradições morais mais marcantes no mundo ocidental. A educação para tal formação moral se torna possível, diante do fato de que os seres humanos possuem uma necessidade intrínseca de se relacionar uns com os outros, não somente para sobreviver, mas também para desenvolverem a sua inteligência e criar diferentes possibilidades de viver; possibilidades que, ao serem escolhidas, excluem outras que tendem a se materializar no individualismo. O capítulo é concluído tendo como embasamento a "busca pela felicidade", já explicitada em Aristóteles, para quem todos os seres humanos buscam ser felizes. Nesse sentido, a aposta da filósofa é na formação moral que incentive uma capacidade criadora e que leve em conta a dimensão comunitária das pessoas e a capacidade de universalização que as mesmas dispõem. A partir dessa formação, minimizam-se conflitos, pois o outro 
passa a ser visto não mais como meio, mas sim como um fim em si mesmo, como um interlocutor com quem se busca construir um mundo melhor.

O capítulo três, de autoria de Felipe Bastos, Raquel Pinho e Rachel Pulcino, apresenta o silenciamento que a heteronormatividade, norma social que define padrões de orientação sexual e também de comportamentos socialmente esperados dos indivíduos, impõe às diferentes orientações sexuais e de gênero no contexto escolar. A partir de estudos sobre documentos nacionais que tratam o assunto da diversidade sexual e pesquisa com professores e alunos, os autores questionam como o tema da diversidade sexual aparece e é tratado na escola. O trabalho tem como foco documentos curriculares que apontam as diretrizes para a educação básica no país e depoimentos de como docentes de ciências e biologia concebem as discussões sobre a diversidade sexual em suas atividades pedagógicas cotidianas. Os autores também consideram a visão dos estudantes para compreender se, no cotidiano escolar, há espaço para que esses questionem, reflitam e discutam sobre a diversidade sexual e de gênero, aspectos tão presentes hoje na escola. Uma das conclusões apresentadas reporta que a escola ainda é um espaço que favorece o silenciamento de determinadas identidades, no âmbito da diversidade de gênero e sexualidade. Defendem que o currículo, os docentes e os educandos devem estar no centro dos debates sobre tais temáticas, para que ocorra uma mudança de postura que vá de encontro ao silenciamento escolar.

No capítulo quatro, Luís Dorvillé, Pedro Teixeira e Camila Soares abordam as relações da escola com as identidades religiosas dos estudantes e as dimensões da inserção da religião na esfera pública. Iniciam seus argumentos, deixando em evidência que as discussões relacionadas à religião e à diversidade religiosa estão cada vez mais presentes em nosso cotidiano e que também foram levadas à escola. Como recorte, os autores discutem as resistências de grupos evangélicos pentecostais e fundamentalistas ao ensino de evolução biológica nas disciplinas de ciência e biologia. Tais resistências se originam na organização de movimentos criacionistas e antievolucionistas que, embora tenham maior influência nos Estados Unidos, possuem um grande número de adeptos em diversas partes do mundo, incluindo o Brasil. A escola pública, segundo os autores, sempre foi um grande espaço de disputa para os criacionistas, devido ao imenso alcance que ela possui e por ser espaço formativo de grande parte da população. Mesmo com o destaque 
dado à evolução biológica, o tema ainda encontra resistências em sala de aula, quando estudantes com crenças fundamentalistas apresentam dificuldades ao grau de complexidade e o grau de abstração dos conteúdos evolutivos. Ao fim do capítulo, os autores defendem a abordagem de mínimos e máximos éticos de Adela Cortina, com a proposta da temática de ensino de evolução ser vista como um mínimo ético e epistemológico ao qual todo estudante deveria ter acesso. Abordam ainda as concepções e interpretações originadas do multiculturalismo, como possibilidades de mediar os conflitos entre as diferentes culturas nas quais estamos imersos.

No quinto capítulo, Giselly Peregrino, pesquisadora do Instituto Nacional de Educação de Surdos (Ines), traz outra fonte de silenciamento no contexto escolar, ao analisar como alunos surdos adultos percebem o preconceito contra a surdez e a libras. O capítulo aponta inicialmente discussões teóricas sobre o conceito de preconceito, entendido como "algo que sobrevive às evidências que poderiam perturbá-lo" e que não deve ser considerado uma incapacidade de entender as diferenças, mas sim algo que envolve juízos passados. O texto apresenta depoimentos e visões dos entrevistados sobre situações nas quais sentiram o preconceito, bem como os desafios de perceber tais ocasiões. No que se refere a libras, Giselly Peregrino aponta que, além das dificuldades do cotidiano, também experienciadas no seio da própria família, o preconceito linguístico ainda é muito evidente. Ela conclui o trabalho de pesquisa apontando os perigos do silenciamento de alunos surdos e do não entendimento da libras, visto que essas são as linguagens possíveis de comunicação da comunidade surda, ainda mais em uma sociedade que se deseja plural. O preconceito, nesse caso, é um processo de silenciamento, que pode gerar a discriminação, humilhação, intolerância, violência física ou simbólica. Nesse sentido, a pesquisadora defende que é necessário repensar juízos de valores que fomentam esse preconceito, bem como favorecer a vivência de novas experiências que se oponham a tais formações.

Pâmela Esteves e Marcelo Andrade abordam, no sexto capítulo, o fenômeno do bullying, aqui entendido como uma violência escolar que parte do não reconhecimento da diferença. O capítulo é dividido em três momentos: no primeiro, os autores apresentam e discutem o conceito de bullying, a partir da dificuldade que os estudantes possuem em lidar com a diferença; no segundo momento, apoiam-se 
na teoria de Charles Taylor, para abordar o reconhecimento social e a noção de identidade; no terceiro momento, o bullying é entendido como parte do processo de banalização da violência e relacionado ao conceito de banalidade do mal de Hannah Arendt. O capítulo é elaborado a partir de uma pesquisa empírica, realizada com estudantes de uma escola de ensino médio da rede estadual do Rio de Janeiro. Concluindo o capítulo, os autores defendem que o entendimento do bullying como uma brincadeira é errôneo. Enfrentar o bullying é investir em uma proposta pedagógica que fomente o pensamento, conceito de Arendt, e novas concepções sobre a diferença.

As autoras Claudia Miranda e Sandra Marcelino analisam, no capítulo sete, um Diário de Bordo, do ano de 2014, confeccionado por uma professora negra de uma escola da rede pública de Queimados, região metropolitana do Rio de Janeiro, que buscava inserir práticas antirracistas em seu cotidiano. Essa análise parte de uma perspectiva teórica intercultural, decolonial e antirracista, que busca, além de compreender o racismo em salas de aulas com crianças e adolescentes majoritariamente negros, apontar possibilidades de intervenção para professoras negras e militantes nessa realidade. As autoras defendem as ressignificações das práticas discursivas e de espaços de construção de saberes, de forma a ampliar as representações de sujeitos subalternizados e silenciados. Outras imersões em contextos escolares formados por uma maioria negra possibilitariam diferentes entendimentos e formações teóricas também no ambiente acadêmico sobre tais questões.

O capítulo oito é de autoria de Mônica Almeida e Mônica Romitelli e nos traz uma reflexão sobre uma das formas de se combater o silenciamento de corte racial, por meio de políticas públicas, como é o caso de políticas de ações afirmativas na educação. Com foco nas políticas raciais no ensino superior, as pesquisadoras se utilizam da comparação dessas em cenários nacional e internacional, para apresentá-las como possibilidades de se combater as desigualdades sociais e de promover a diversidade cultural no campo educacional. No início do trabalho, elas argumentam que as ações afirmativas são baseadas na busca por pluralidade cultural e por uma reparação histórica que visa a promover a diversidade e maior distribuição de justiça social. Indo além das motivações para as políticas raciais, Almeida e Romitelli defendem que o princípio da diversidade é uma forma de 
promoção de uma sociedade mais justa e que valorize as diferenças. O rompimento do silenciamento de identidades socialmente marginalizadas, neste trabalho, caminha junto com atuações políticas e jurídicas, que respaldam atuações no meio pedagógico. A representação de identidades marginalizadas após a implementação da política de cotas ganhou mais vez e voz, bem como auxiliou na promoção de empoderamentos. Por fim, defendem que a escola e a universidade ainda são espaços fecundos de formação de novas possibilidades de superação de silenciamentos, ao evocar respeito mútuo na construção de uma sociedade mais justa.

Concluindo a obra, Helena Araújo e Monique Longo apresentam um ensaio teórico baseado em Hannah Arendt, Paul Ricouer e Beatriz Sarlo. As pesquisadoras defendem a proposta de uma "educação para o recomeço", para a superação dos silenciamentos expostos ao longo da obra e de muitos outros presentes no cotidiano escolar e também em nossa sociedade. O pensamento, como forma de exercício da compreensão e o perdão, são, segundo as autoras, importantes ferramentas para a superação dos preconceitos. O pensamento, segundo Arendt, é um esforço de compreensão do mundo e se reconciliar com a forma com que se age nele. $O$ perdão é apresentado pelas autoras como forma de reconhecer os limites humanos, optar pela justiça e rememorar o acolhimento e a superação do erro. Assim, a defesa e busca de uma "memória feliz", em uma sociedade tão plural, possibilita o ato de pensar e também de revisitar o passado, com vistas a criar um presente e um futuro mais justo e igualitário, dado que a memória não é compreendida somente como um direito, mas também como um dever e uma necessidade moral, jurídica e política.

Os trabalhos reunidos nesta obra possibilitam maior entendimento dos temas do silenciamento e de seu enfrentamento a partir de uma aposta na educação intercultural e na ética do discurso. Dentro do contexto escolar, as pesquisas realizadas pelo Gecec/PUC-Rio, apontam que os chamados "diferentes" são os que encontram mais barreiras para se expressar e ter as suas vozes e identidades reconhecidas. As diferenças de classe, gênero, raça, orientação sexual, crenças religiosas, de origens, de pertencimentos e afins são as mais silenciadas na escola. A uniformidade como defesa errônea da igualdade ainda se faz bastante presente nos espaços educacionais. A partir de diferentes óticas, a obra oferece contribuições 
para reflexões sobre conflitos do cotidiano escolar e possibilidades de formações de novas epistemologias, teorias e práticas pedagógicas. 